\title{
The Paracoccus denitrificans ccmA, B and $C$ genes: cloning and sequencing, and analysis of the potential of their products to form a haem or apo- c-type cytochrome transporter
}

\author{
M. Dudley Page, ${ }^{1,2}$ David A. Pearce, ${ }^{1} \dagger$ Hilary A. C. Norris ${ }^{1}$ \\ and Stuart J. Ferguson ${ }^{1,2}$ \\ Author for correspondence: Stuart J. Ferguson. Tel. +44 1865 275240. Fax +441865 275259 \\ e-mail: ferguson@bioch.ox.ac.uk
}

1 Department of

Biochemistry, University of

Oxford, South Parks Road,

Oxford OX1 3QU, UK

2 Oxford Centre for

Molecular Sciences, New

Chemistry Laboratory,

South Parks Road, Oxford

OX1 3QT, UK
Two c-type cytochrome deficient mutants of Paracoccus denitrificans, HN49 and HN53, were isolated by Tn5 mutagenesis and screening for failure to oxidize dimethylphenylenediamine (the Nadi test). Both were completely deficient in c-type cytochromes. Genomic DNA flanking the site of Tn5 insertion in HN53 was cloned by marker rescue and a $3 \cdot 1 \mathrm{~kb}$ region sequenced. Three of the genes, designated $\mathrm{ccmA}, \mathrm{ccmB}$ and $\mathrm{ccmC}$, present in this region are proposed to encode the components of a membrane transporter of the ABC (ATP-binding cassette) superfamily, which is similar to a group of transporters postulated to translocate either haem or apocytochromes $c$. The Tn5 elements in HN49 and HN53 were shown to be inserted in ccmB and ccmA, respectively. Sequence analysis suggested that both $\mathrm{CcmB}$ and $\mathrm{CcmC}$ have the potential to interact with $\mathrm{CcmA}$ and thus that the three gene products probably associate to form a complex with $(\mathrm{CcmA})_{2}-\mathrm{CcmB}-\mathrm{CcmC}$ stoichiometry; it also indicated a lack of similarity between $\mathrm{CcmB}$ and $\mathrm{CcmC}$ and the membrane-integral components of transporters mediating uptake of haem or other iron complexes. Supplementation of growth media with haem did not stimulate c-type cytochrome formation in HN49 or HN53, although it elevated levels of soluble haemoproteins and membrane-bound cytochromes $b$, suggesting that exogenous haem can traverse both outer and inner membranes of $P$. denitrificans. HN49 and HN53 accumulated apocytochrome $c_{550}$ to much lower levels than other c-type cytochrome deficient mutants of $P$. denitrificans but expression and translocation of an apocytochrome $\mathrm{C}_{550^{-}}$ alkaline phosphatase fusion protein and apocytochrome $\mathrm{cd}$, were unaffected in HN53. The results suggest that the substrate for the putative CcmABCtransporter is probably neither haem nor c-type apocytochromes.

Keywords: Paracoccus denitrificans, $c$-type cytochrome biogenesis, apocytochrome, putative $\mathrm{ABC}$-transporter, haem

\section{INTRODUCTION}

Cytochromes $c$ are distinguished from cytochromes of

† Present address: Department of Biochemistry, University of Rochester School of Medicine and Dentistry, 601 Elmwood Avenue, Rochester, NY 14642, USA.

Abbreviations: ABC, ATP-binding cassette; PBT, periplasmic-bindingprotein-dependent transporter.

The GenBank accession number for the sequence reported in this paper is Z71971. other classes by covalent attachment of the haem moiety to the cytochrome polypeptide via thioether links between the two haem vinyl groups and the thiol groups of the two cysteine residues in the conserved motif Cys$\mathrm{X}$-Y-Cys-His. How this important post-translational modification is achieved in either mitochondria or bacteria is currently unknown. A number of genes required for c-type cytochrome maturation in Gramnegative bacteria have recently been described (reviewed by Thöny-Meyer et al., 1994; Crooke \& Cole, 1995). Of these, the Bradyrbizobium japonicum cycVW genes 
(Ramseier et al., 1991) and the homologous helAB genes in Rhodobacter capsulatus (Beckman et al., 1992) appear to code for an ATP-driven membrane transporter of the ABC (ATP-binding cassette) superfamily (Ames et al., 1992; Higgins, 1992; Reizer et al., 1992). Homologous genes (designated $c c m A B$ ) have subsequently been identified in Escherichia coli (Richterich et al., 1993; Thöny-Meyer et al., 1995; Grove et al., 1996), Haemophilus influenzae (Fleischmann et al., 1995) and Rhizobium etli (Aguilar \& Soberon, 1996). The cycV/belA/ccmA genes code for the ATP-binding subunit of the transporter, while $c y c W / b e l B / c c m B$ code for an integral membrane component, but the function, subunit composition and stoichiometry of the transporter are uncertain. The R. capsulatus belC and E. coli and $H$. influenzae ccm $C$ genes and the homologous ORF orf 263 in B. japonicum also code for integral membrane proteins which may be components of the putative transporter, but the situation is unclear because whilst belC is essential for $c$-type cytochrome biogenesis (Beckman et al., 1992), orf263 reportedly is not (Ramseier $\mathrm{et} \mathrm{al.,1991).} \mathrm{No} \mathrm{gene} \mathrm{corresponding} \mathrm{to} \mathrm{ccmC}$ has yet been reported in $R$. etli. The substrate of the putative $\mathrm{CcmABC} / \mathrm{HelABC} / \mathrm{CycVW}( \pm$ orf 263 gene product) transporter is also unknown. It has been suggested that this may be haem (Ramseier et al., 1991; Beckman et al., 1992); if $c$-type cytochrome maturation occurs in the periplasm, as is suggested by an increasing body of evidence (Page \& Ferguson, 1989, 1990; Sambongi \& Ferguson, 1994a; Thöny-Meyer et al., 1996), then provision must be made for the translocation of haem from the cytoplasm to the periplasm prior to its reaction with apocytochromes $c$. The finding that the ccm $A B C /$ helABC/cycVW-orf263 loci, unlike those of the bacterial periplasmic-binding-protein-dependent transporters, do not contain a gene coding for a periplasmic component has been taken as evidence that the putative transporter may be an exporter rather than an importer (Beckman et al., 1992). Some support for the idea that haem translocation to the periplasm is required for assembly of certain cytochrome components in bacteria has come from study of the $E$. coli cydDC genes, which code for the subunits of a heterodimeric $\mathrm{ABC}$-transporter required for assembly of the $b d$-type cytochrome oxidase and which, it has been suggested, may transport the $d$-type haem to the periplasmic face of the membrane prior to its association with the oxidase apoprotein (Poole et al., 1993). Alternatively, the putative CcmABC/HelABC/ CycVW ( \pm orf 263 gene product) transporter might serve to translocate apocytochromes $c$ (Ramseier et al., 1991; Beckman et al., 1992), or even both the latter plus haem (Thöny-Meyer et al., 1994).

The first reports of the accumulation of apocytochromes $c$ in the periplasm of a Gram-negative bacterium were for a mutant of Paracoccus denitrificans (Page \& Ferguson, 1989, 1990). Subsequently, apocytochrome $c_{550}$ has been detected in a number of other mutants of this organism, including those deficient in 5-aminolaevulinate synthase (DP104; Page \& Ferguson, 1994) and $c y c H$ (DP108; Page \& Ferguson, 1995). Apocytochromes $c$ have not been readily detected in other bacteria in which $c$-type cytochrome biogenesis has been studied by the disruption of genes required for this process. It is possible that the stability of such apocytochromes varies with the locus of mutations preventing the formation of holo- $c$-type cytochromes. Any such differential stability could provide important clues as to the roles of the gene products identified as participating in $c$-type cytochrome biogenesis. Given the background of work on c-type cytochrome biogenesis in $P$. denitrificans (Page \& Ferguson, 1989, 1990, 1994, 1995), and the vast amount of information availible on $c$-type cytochromes in this organism (Steinrücke \& Ludwig, 1993), it is important that other genes required for $c$-type cytochrome biosynthesis in this organism be identified and characterized alongside studies of the consequences of their inactivation. We now report the isolation of mutants of $P$. denitrificans with Tn5 insertions in $c \mathrm{cmA}$ or $c c m B$ and the cloning and sequencing of the $P$. denitrificans $c c m A B C$ gene region. The availability of these additional sequences has permitted us to make certain new deductions regarding the probable organization of the putative CcmABC/HelABC/ CycVW( \pm orf263 gene product) transporter. Furthermore, the two mutants proved to have a novel phenotype in respect of apocytochrome $c_{550}$ accumulation.

\section{METHODS}

Bacterial strains, plasmids and growth conditions. The following strains and plasmids were used in this study: $P$. denitrificans PD1222 (restriction deficient; de Vries et al., 1989) and DP108 (c-type cytochrome deficient; Page \& Ferguson, 1995); E. coli JM83 [ara $\Delta$ (lac-proAB) $r s p L \phi 80$ lac Z $\Delta \mathrm{M} 15]$ was used for maintenance and propagation of plasmids; NM554 [recA1 araD139 $\Delta$ (ara-leu)7696 $\Delta($ lac $) 7 A$ galU galK hsdR strA (Str $\left.{ }^{r}\right) \operatorname{mcr} A$ mcrB] for cosmid cloning; S17-1 (C600::RP-4 2-Tc::Mu-Km::Tn7 hsdR hsdM ${ }^{+}$recA) for mobilization of pSUP202::Tn5; pUC18 (Yanisch-Perron et al., 1985); pBluescriptII SK(+) and pWE16 (Stratagene); pEPD60 (Stoll et al., 1996); pKN2 (which comprises the internal HindIII fragment of Tn5 cloned in pBR322; Sockett \& Armitage, 1991); pRK2013 (Ditta et al., 1980); pSUP202 and pSUP202::Tn5 (Simon et al., 1983).

$P$. denitrificans strains were grown aerobically in the minimal medium of Burnell et al. (1975) containing either sodium succinate $(50 \mathrm{mM})$ or choline $(0.5 \%, \mathrm{w} / \mathrm{v})$. Cultures were harvested in either late $\left(O D_{650} 1.2\right.$, equivalent to $0.6-0.8 \mathrm{mg}$ dry weight of cells per $\mathrm{ml}$ ) or early $\left(\mathrm{OD}_{650} 0 \cdot 6\right.$, equivalent to $0.3-0.4 \mathrm{mg}$ dry weight of cells per $\mathrm{ml}$ ) exponential phase, as indicated in the text. Media for anaerobic growth contained $100 \mathrm{mM} \mathrm{KNO}_{3}$ or were periodically sparged with $\mathrm{N}_{2} \mathrm{O}$. The ability of exconjugants to utilize methanol was assessed using the medium of Alefounder \& Ferguson (1981). E. coli strains were grown in LB (Luria-Bertani medium). Antibiotics were added to the following concentrations (in $\mu \mathrm{g} \mathrm{ml}^{-1}$ ): ampicillin, 50; kanamycin and spectinomycin, 25 (for E. coli) or 100 (for $P$. denitrificans); streptomycin, 60; rifampicin, 100 . Stock solutions of haemin were prepared as described by Karim et al. (1993).

Tn5 mutagenesis and screening of exconjugants. $P$. 
denitrificans PD1222 was mutagenized by conjugation with $E$. coli S17-1(pSUP202::Tn5) as described by Bagdasarian et al. (1981). After mating for $12-22 \mathrm{~h}$ at $37^{\circ} \mathrm{C}$, cells were plated onto nutrient agar containing kanamycin, spectinomycin and rifampicin. When exconjugants appeared the plates were flooded with the Nadi reagent; colonies which did not exhibit a dark blue colouration after $15 \mathrm{~s}$ were picked and immediately inoculated into $2 \mathrm{ml} \mathrm{LB}$ for growth.

Analytical methods. Induction of apocytochrome $c d_{1}$ synthesis in DP108 and HN53, preparation of total soluble and periplasmic protein fractions and solubilized membranes from $P$. denitrificans strains, SDS-PAGE, nondenaturing PAGE, staining for haem, determination of protein, the Nadi test, production of antibodies to apocytochrome $c_{550}$, immunoblotting of proteins separated by SDS or nondenaturing PAGE and analysis of apocytochrome $c_{550}$ and apocytochrome $c d_{1}$ localization were as described previously (Page \& Ferguson, $1989,1994)$. Periplasmic fractions were concentrated where neccessary using the Amicon Centricon system (YM3 membrane) after dialysis against $20 \mathrm{mM}$ Tris $/ \mathrm{HCl} \mathrm{pH} 7 \cdot 5$ containing $1 \mathrm{mM}$ EDTA plus $1 \mathrm{mM}$ [4-(2-aminoethyl)benzenesulfonyl fluoride]. $\mathrm{HCl}$ and centrifugation. Mouse anti-nitrite reductase serum was a gift from $\mathrm{Dr}$ A. de Boer (Vrije Universiteit, Amsterdam); in this case a horse anti(mouse IgG)-alkaline phosphatase conjugate was used as the secondary antibody in immunoblotting. Alkaline phosphatase activities were determined as described by Stoll et al. (1996). Spectra were recorded on Aminco DW2000 or Perkin Elmer Lambda2 spectrophotometers.

DNA manipulations, sequencing and analysis. General DNA manipulations were as described by Sambrook et al. (1989). The DNA region around the site of $\operatorname{Tn} 5$ integration in HN53 was sequenced following subcloning. DNA fragments generated by cutting with ApaI, BglII, EcoRV, MscI, NcoI, TaqI and Xhol were cloned in pUC18 or pBluescript and sequenced using Sequenase version 2.0 and M13 universal primers. Gaps in the sequence thus obtained were bridged using custom primers. Tn5-flanking DNA fragments cloned from HN49 and HN53 were sequenced using the primer $5^{\prime}$ CGTTCAGGACGCTAC-3', complementary to bases 17-34 within the Tn5 inverted repeat (Auerswald et al., 1981). Sequence analysis made use of the University of Wisconsin Genetics Computer Group software package releases 7.0 and 8.0 (Devereux et al., 1984). Database searches were made using the program BLAST (Altschul et al., 1990). Membranespanning $\alpha$-helices were assigned for multiple sequences by the statistical method of Persson \& Argos (1994). These assignments were in agreement with assignments for individual sequences made using the statistical/topology analysis of Jones et al. (1994). In all cases a minimum transmembrane helix length of 21 amino acids was imposed. The orientation of transmembrane $\alpha$-helices was assigned for individual sequences using the algorithm of Jones et al. (1994); in all cases the result agreed with that obtained by simple assignment of topology using the 'inside positive' rule of von Heijne (1992). There were no discrepancies in the predicted topology of the same protein from different species.

Plasmid pEPD60 was transferred to PD1222, DP108 or HN53 in triparental conjugations using pRK2013 as helper plasmid (Ditta et al., 1980). After mating, cells were plated onto minimal succinate agar containing streptomycin and rifampicin (for PD1222) or streptomycin, rifampicin and kanamycin (for DP108 and HN53). In the case of DP108 and HN53, exconjugants were rechecked for the Nadi-negative phenotype.

\section{RESULTS}

\section{Isolation and preliminary characterization of mutants HN49 and HN53}

Approximately 200000 kanamycin-resistant exconjugants from three independent matings between $E$. coli S17-1(pSUP202:: Tn5) and P. denitrificans PD1222 were screened for the ability to oxidize dimethylphenylenediamine (the Nadi reaction; Marrs \& Gest, 1973) and for the ability to grow aerobically with methanol. Of 63 Nadi-negative exconjugants, 9 were also unable to utilize methanol. This paper describes the properties of two of these mutants, designated HN49 and HN53, selected for study on the basis of their failure to accumulate the cytochrome $c_{550}$ polypeptide (see below). Both HN49 and HN53 were also incapable of aerobic growth on methylamine, or of anaerobic growth with either nitrate or nitrous oxide as terminal electron acceptor. In spite of these defects in electron transport,
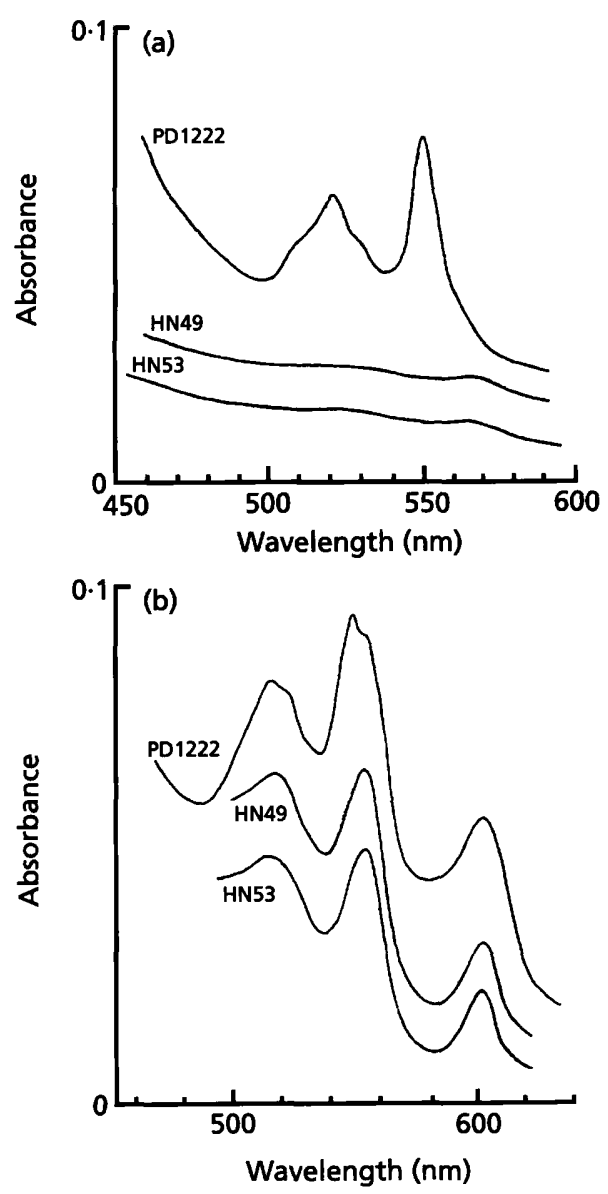

Fig. 1. Visible absorption spectra of total soluble extracts (a) and dodecylmaltoside-solubilized membranes (b) from $P$. denitrificans PD1222, HN49 and HN53. Strains were grown with choline as carbon source to maximize expression of polypeptides for c-type cytochromes. Total soluble extracts were adjusted to $15 \mathrm{mg}$ protein $\mathrm{ml}^{-1}$. Membrane samples contained $10 \mathrm{mg}$ dodecylmaltoside-solubilized protein $\mathrm{ml}^{-1}$. All samples were reduced with sodium dithionite and spectra measured against a buffer reference. 


\section{$\begin{array}{llllll}1 & 2 & 3 & 4 & 5 & 6\end{array}$}

Fig. 2. $P$. denitrificans mutants HN49 and HN53 accumulate only low levels of apocytochrome $c_{550}$, but these levels are higher in cells grown to early, rather than late, exponential phase. Total soluble extracts were analysed by SDS-PAGE and immunoblotting with antisera raised against the chemically prepared apocytochrome. Lanes 1, 2, 3 and 4, PD1222, DP108, HN49 and HN53, respectively, all grown to late exponential phase $\left(O D_{650} 1 \cdot 1-1 \cdot 2\right)$; lanes 5 and $6, H N 49$ and HN53, respectively, grown to early exponential phase $\left(O D_{650} 0.6-0.7\right)$. Lanes contained approximately $20 \mu \mathrm{g}$ total protein.

both mutants grew aerobically on either succinate minimal media or LB at rates very similar to those of the parental strain PD1222. In these respects they closely resemble the $c$-type cytochrome deficient mutants of $P$. denitrificans described previously (Willison \& John, 1979; van Verseveld et al., 1981; Harms et al., 1985; Page \& Ferguson, 1994, 1995).

\section{Mutants HN49 and HN53 are pleiotropically deficient in c-type cytochromes}

Spectroscopic analysis of both total soluble and membrane fractions prepared from HN49 and HN53 grown on choline, a gratuitous inducer of $c$-type cytochromes associated with methylotrophic growth (Harms \& van Spanning, 1991), indicated that both mutants were devoid of $c$-type cytochromes (Fig. 1a, b). However, membranes from both strains contained $a$ - and $b$-type cytochromes at levels equivalent to those observed in PD1222 (Fig. 1b). The assembly of a residual level of membrane-bound $c$-type cytochromes in the $c y c H$ mutant DP108 was previously inferred from the presence of a shoulder at $550 \mathrm{~nm}$ to the $b$-type cytochrome $560 \mathrm{~nm}$ absorbance peak (Page \& Ferguson, 1995); this shoulder was absent from spectra recorded from HN49 or HN53 membranes. The cytochrome $c_{1}$ and $c_{552}$ polypeptides were absent from membranes of HN49 and HN53 as judged by SDS-PAGE and immunoblotting (data not shown). The complete absence of cytochrome $c_{1}$ from HN49 and HN53 was also indicated by the failure of the two mutants to grow anaerobically with $\mathrm{N}_{2} \mathrm{O}$ as terminal electron acceptor; it has been demonstrated that the cytochrome $b c_{1}$ complex is required for $\mathrm{N}_{2} \mathrm{O}$ respiration by $P$. denitrificans (Moir, 1993). SDS-PAGE and haem staining analyses showed that none of the four major soluble, or three major membrane-bound $c$-type cytochromes, synthesized by choline-grown PD1222 (Harms \& van Spanning, 1991; Page \& Ferguson, 1994, 1995) were detectable in total soluble or membrane fractions of choline-grown HN49 or HN53 (data not shown). Thus the genes disrupted in HN49 and HN53 are absolutely required for the biogenesis of all $c$-type cytochromes in P. denitrificans.

\section{Mutants HN49 and HN53 accumulate only trace amounts of apocytochrome $c_{550}$}

All the previously described $c$-type cytochrome deficient mutants of $P$. denitrificans (HUUG25, PD1219, DP104 and DP108) accumulated apocytochrome $c_{550}$, which was readily detected by SDS-PAGE or nondenaturing PAGE followed by immunoblotting of total soluble or periplasmic extracts (Page \& Ferguson, 1990, 1994, 1995). In contrast, the cytochrome $c_{550}$ polypeptide could not be detected in periplasmic fractions from mutants HN49 and HN53 and was present only in trace amounts in total soluble extracts as judged by SDSPAGE and immunoblotting (Fig. 2). This was the case when cells were grown to late exponential phase, as for previous analyses of apocytochrome $c_{550}$ accumulation (Page \& Ferguson, 1990, 1994, 1995). When cells were harvested in early exponential phase, however, detectable (but still low) levels of the cytochrome $c_{550}$ polypeptide were observed (Fig. 2). Harvesting of DP108 in early exponential phase also resulted in the detection of an elevated level of apocytochrome $c_{550}$ in this mutant. On SDS-PAGE the cytochrome $c_{550}$ polypeptide in total soluble extracts of HN49 and HN53 was indistinguishable from the holocytochrome in extracts of the wildtype strain PD1222, indicating proteolytic removal of the signal sequence and thus translocation to the periplasm; a periplasmic location for the cytochrome $c_{550}$ polypeptide in the two mutant strains was confirmed by fractionation of cells into periplasm, cytoplasm and membranes followed by SDS-PAGE and immunoblotting (data not shown). That the immunoreactive polypeptide was apocytochrome $c_{550}$ rather than the holocytochrome was confirmed by nondenaturing PAGE and immunoblotting after concentrating periplasmic fractions from cells grown to early exponential phase (data not shown). These results indicate that apocytochrome $c_{550}$ is expressed and translocated to the periplasm in both mutants but that its synthesis, efficiency of translocation or stability, either alone or in combination, are reduced in HN49 and HN53 compared to other $c$-type cytochrome deficient mutants of $P$. denitrificans we have analysed (Page \& Ferguson, 1990, 1994, 1995).

\section{Cloning and analysis of transposon-flanking DNA from HN53 and HN49}

Hybridization of HN53 chromosomal DNA with the internal HindIII fragment from $\mathrm{Tn} 5$ indicated the presence of a single copy of the transposon in the HN53 genome; failure to hybridize with pSUP202 indicated the absence of cointegrated vector DNA. Using the kanamycin-resistance determinant of $\operatorname{Tn} 5$ as a selectable marker, HN53 genomic DNA contiguous with the $5^{\prime}$ end of the Tn 5 element was cloned in pUC18 as a $4.2 \mathrm{~kb}$ Sall fragment comprising the $5^{\prime}$ region of $\operatorname{Tn} 5$ plus $1.4 \mathrm{~kb}$ of HN53 genomic DNA. 


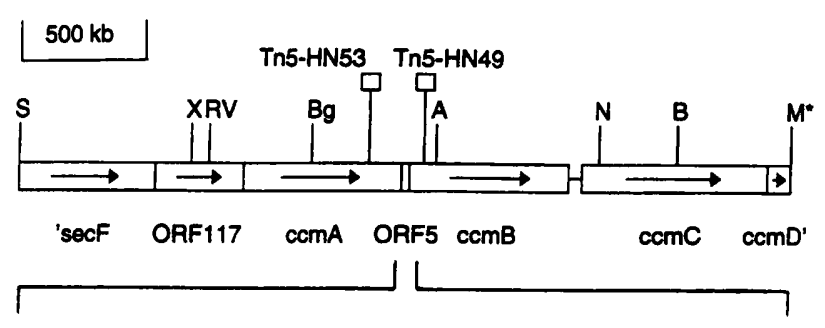

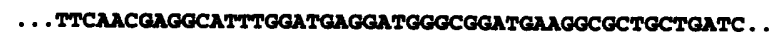

. F N E A $F$ G

M $\quad$ K $\mathbf{A}$ I $\mathbf{I}$ I $\ldots$

Fig. 3. Map of the $P$. denitrificans ccmABC gene region. Arrows indicate the predicted direction of transcription of the assigned ORFs. The sites of Tn5 integration in mutants HN49 and HN53 are as indicated. The structure of the orf5 region is shown beneath the map. Restriction sites: A, Apal; B, BamHI; Bg, Bg/lI; M, Mscl; N, Ncol; RV, EcoRV; S, Sall; X, Xhol. *, Site not unique.

HN53 genomic DNA contiguous with the $3^{\prime}$ end of the Tn 5 element was recovered by cosmid cloning using the kanamycin-resistance determinant of $\operatorname{Tn} 5$ as a selectable marker (Viebrock \& Zumft, 1987). Cosmids carrying the Tn5 element were digested with SalI and the two restriction fragments hybridizing with the $\mathrm{pKN} 2$ insert were isolated and cloned. One of these was the $4.2 \mathrm{~kb}$ Sall fragment described above; the other was a $6.7 \mathrm{~kb}$ SalI fragment comprising the $3^{\prime}$ end of Tn 5 plus $3.7 \mathrm{~kb}$ of HN53 genomic DNA.

When Tn5 DNA was hybridized to Sall-digested HN49 chromosomal DNA four hybridizing DNA fragments were observed, indicating the presence of two copies of $\mathrm{Tn} 5$ in the HN49 genome. Cointegrated vector DNA was absent. HN49 genomic DNA contiguous with the $5^{\prime}$ end of one of the Tn5 elements was cloned in pUC18 as a $4.4 \mathrm{~kb}$ Sall fragment comprising the $5^{\prime}$ region of $\operatorname{Tn} 5$ plus $1.6 \mathrm{~kb}$ of $\mathrm{HN} 49$ genomic DNA.

All of the cloned genomic DNA upstream of the $\operatorname{Tn} 5$ element in HN53 and 1673 bp of DNA downstream of it was sequenced; this DNA region contained four complete and two partial large ORFs (Fig. 3) with a codon usage typical for genes in P. denitrificans (Steinrücke \& Ludwig, 1993).

The predicted protein products of the second, third, and fourth complete large ORFs identified exhibited extensive homology to Hel A, B, and C of Rhodobacter capsulatus (Beckman et al., 1992), the cycVW-orf263 gene products of B. japonicum (Ramseier et al., 1991) and CcmA, B and C of E. coli (Richterich et al., 1993; Thöny-Meyer et al., 1995; Grove et al., 1996), and they were termed $\mathrm{CcmA}, \mathrm{CcmB}$, and $\mathrm{CcmC}$ in accordance with the E. coli nomenclature. $c \mathrm{~cm} A$ and $c \mathrm{cmB}$ were separated by a short ORF, orf5 (shown in Fig. 3), while $c \mathrm{cmB}$ and $\mathrm{ccmC}$ were separated by an untranslated region of $52 \mathrm{bp}$. The predicted product of the first complete ORF (orf117) was similar to that of the orf124 immediately upstream of belA in $R$. capsulatus (Beckman et al., 1992), while the predicted product of the $5^{\prime}$ partial ORF was similar to the C-terminal regions of the predicted products of the E. coli secF gene (Gardel et al., 1990) and a secF-like gene located immediately upstream of orf124 in R. capsulatus (Beckman et al., 1992). The predicted product of the 3' partial ORF, termed $c c m D$, exhibited similarity to the $\mathrm{N}$-terminal regions of $R$. capsulatus HelD, B. japonicum CycX and E. coli CcmD (Beckman \& Kranz, 1993; Ramseier et al., 1991; Richterich et al., 1993). The start codons of $c \mathrm{cmB}$, $c c m C, c c m D$, orf117 and orf5 were all preceded by potential ribosome-binding sites at distances of 5-7 bp, but a strong ribosome-binding site was not observed upstream of $c \mathrm{cmA}$, a feature which has also been noted for belA in R. capsulatus (Beckman et al., 1992).

The organization of the $P$. denitrificans $c c m A B C$ gene region thus closely resembles that reported for the corresponding region in Rhodobacter capsulatus (Beckman \& Kranz, 1993), consistent with the close evolutionary relationship between these two organisms. An interesting feature of the $P$. denitrificans ccm $A B C$ region is the small ORF, orf5, located between $c c m A$ and $c c m B$. The start codon of orf5 overlapped the stop codon of $c \mathrm{cmA}$, and its stop codon overlapped the start codon of $c \mathrm{cmB}$, suggesting that the three genes may be translationally coupled (Kozak, 1983). Thöny-Meyer et al. (1994) have noted that there are ORFs between the corresponding genes $c y c V$ and $c y c W$ in B. japonicum (orf105) and belA and belB in R. capsulatus (orf41); they have suggested that, since there is no homology between the predicted products of orf 105 and orf 41 , these may serve to translationally couple the two pairs of genes. In Rhizobium etli, $c \mathrm{~cm} A$ and $c \mathrm{cmB}$ are also separated by an ORF, orf80 (Aguilar \& Soberon, 1996), which shows no similarity to either orf105 or orf 41 . In all three organisms, as in P. denitrificans, the start and stop codons of the intervening ORF overlap the stop and start codons of the preceding and succeeding genes. In $E$. coli the start codon of $c c m B$ overlaps directly with the stop codon of $\mathrm{ccm} A$ so that the two genes may be translationally coupled without there being an intervening ORF.

Sequencing indicated that the $\operatorname{Tn} 5$ element present in HN53 was located in the $3^{\prime}$ region of $c \mathrm{cmA}$ and that one of the Tn5 elements present in HN49 was located in the 5 region of $c \mathrm{cmB}$. Genomic DNA contiguous with the second Tn5 element in HN49 was not recovered, so that its position in the $P$. denitrificans genome is currently unknown. For this reason, HN49 was excluded from some of the analyses described below.

\section{The predicted $\mathrm{CcmA}, \mathrm{CcmB}$ and $\mathrm{CcmC}$ gene products; sequence analysis}

The $P$. denitrificans $c c m A$ gene encodes a predicted protein of 211 amino acids which is highly similar to Rhodobacter capsulatus HelA, B. japonicum CycV, and CcmA in E. coli, H. influenzae or Rhizobium etli and to the ATP-binding subunits or domains of many other ABC membrane transporters. $P$. denitrificans $\mathrm{CcmA}$ contained the conserved Walker A and B motifs that 
(a)

pdccma

MNLLAVRDLAVARGGLRAVEGVCF N N AGGALVVRGPNGIGA ITLL

RT T A G Q PLVSGVIEAAPDAIAYAGHS DGLKPALTVTENLRF WAEI

FGGRNI DAALEA MNLRDLANRPAHALSAGQKRRLGVARLMVTGR D

III I IIPT VSLDRDSGLALFAAIVRAHLGRGGAAVIATHIDLGLPEA

(b)

0

pdccmb

rchelb

bjcycw

reccmb

ecccmb

hiccmb

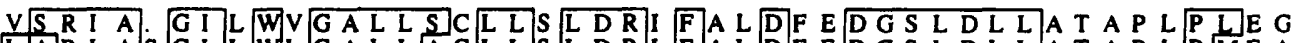
LAAR I A S G I L WL G A L L A C C L L S L D R L I F A L D F E D G S L L D L L A T A P I P L S RLG T P I L WL G A L L A S L L T L D R L F M A D H E D G S L D L I T M S R T P L E L L S R IG P A I V WI GA L L S A L L GL DR L F Q A ER DD G S L D LML MOE T P L V L L A R I A P G I I WV A A L L S S L L A L

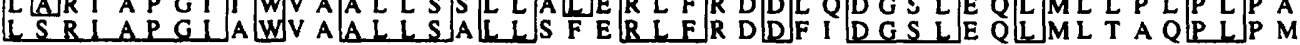

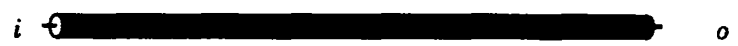

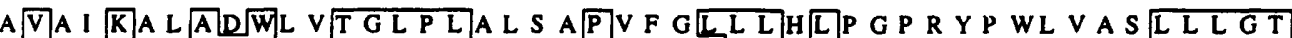

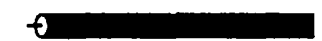
VVVT I K A L A H WI T T G L P L V L A A P L F A V VL L H L P A P A Y L WL E V S L L L G T 135 A C A A K A L A H WL A A G L P L I V A T P V L G L L L L N L D M V A T G A V A L T L L A A T 138 T TIL V K C F A H WT A T G L P L V I A S P L L GLLFMN MDE A A I G A T MLL T L L V V G S V V L A K V MA H WM V T G L P L L I L S P L V A MLLG MDV Y G WO V MALL T L L L G T T A L A K V V A A H WL L T GLPLI L L S P I A A LLLلS ILE V N I WWA L VLLLLLGT

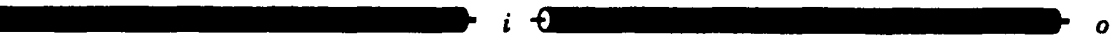

pdccmb

pdccmb

rchelb
bjcycw

reccmb

eccomb

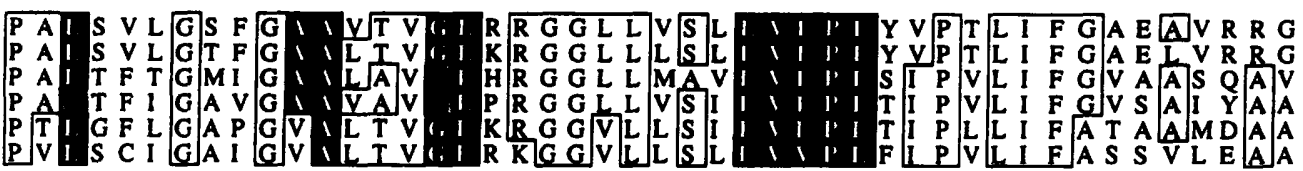

Fig. 4. For legend see facing page.

have been identified in all nucleotide-binding proteins (Walker et al., 1982), together with the invariant glycine residue located just upstream of the Walker A motif (Higgins et al., 1986)(Fig. 4a).

The $P$. denitrificans $c c m B$ and $c c m C$ genes encode predicted integral membrane proteins of 215 and 242 amino acids, respectively, both with six membranespanning helices oriented such that their $\mathrm{N}$ - and $\mathrm{C}$ - terminal regions are cytoplasmic (Fig. 4); this is typical for the membrane-integral components of ABCtransporters (Higgins, 1992), but has not been deduced previously for these components of the putative $\mathrm{CcmABC} / \mathrm{HelABC} / \mathrm{CycVW}$ ( \pm orf 263 gene product) transporter. $\mathrm{CcmB}$ and $\mathrm{CcmC}$ are highly homologous to the predicted protein products of helB and belC in Rbodobacter capsulatus, cycW and orf 263 in B. japonicum, together with $c \mathrm{cmB}$ and $\mathrm{ccm} C$ in both 
(c)

pdccmc

rchelc

bjo263

ecceme

eccemc

hiccmc
pfcyt 1

pdecmc

rchelc

bjo263

ecccmc

hiccme

pfoyt 1

pdecmo

rehelc

rchelc
bjo263

ecceme

hicemc

pfeyt1

podcemc

rchelc

bjo263

eccomc

hiccme

pfeyt 1

pdccmc

rchelc

bjo263

eccemc

hiccme

pfeyt 1

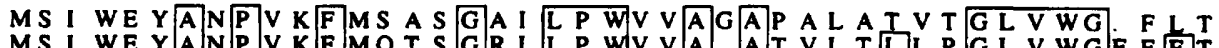

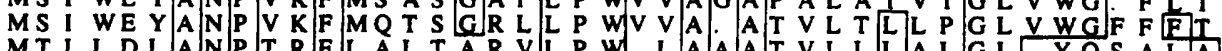

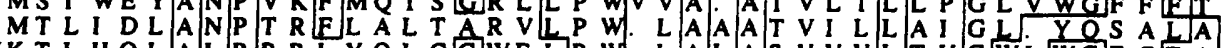

M W K T L H Q L L

M WK WL H P $\mathbf{Y}$ A

M N WT WF H K L G S

0 - $i$

PE DYK OGA T VK IIFL HVPAAL MAI N I WL MMLVTS L I WLI RR H H V S A

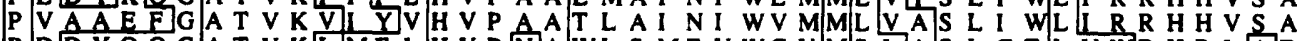
P D D Y Q Q G A T V K I MF I H V P WA P A D Y Q Q G P A D Y O O G

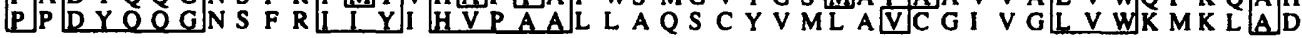

$i €-0$

0

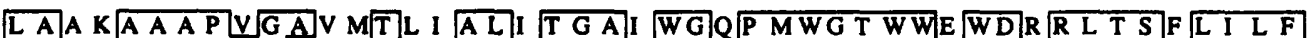

L A A K A A A A P I G G M

VA A

L A V A A A MA P I G A

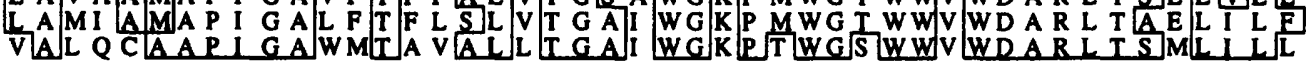
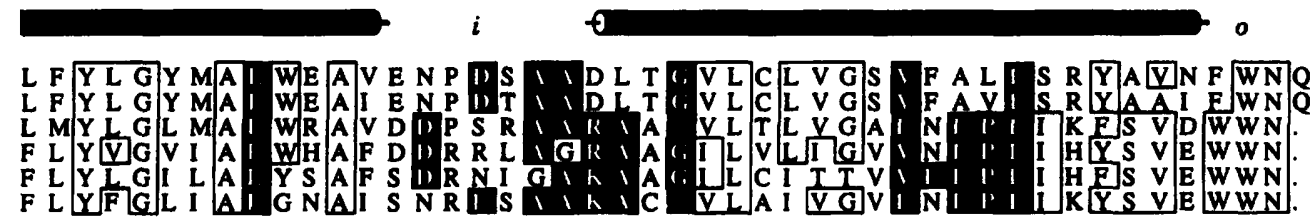

0

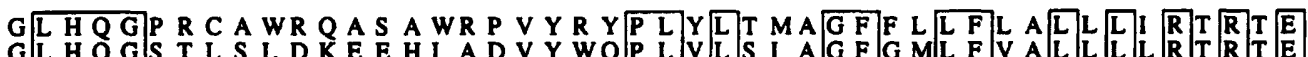

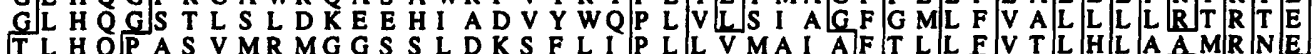

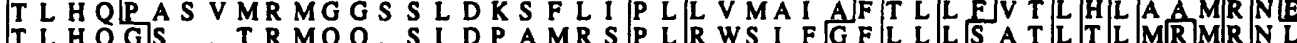

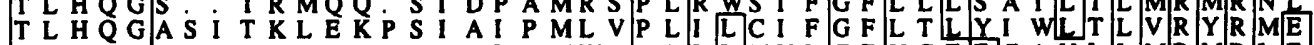

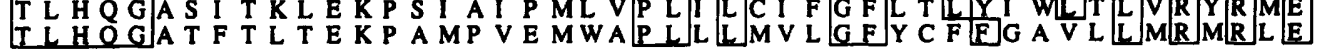

42

42

41

44

44

88

88

87

90

91

134

134

133

136

136

137

180

180

178

181

181

182

226

226

224

224

226

227

pdecme

rchelc

bjo263

ecccmc

pfcytI

I

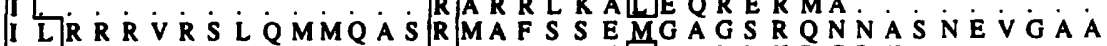

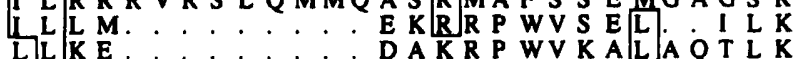

$\mathbf{L} \mathbf{L}_{\mathbf{K}} \mathbf{K}$.

E A[R]A S WVK VEV Q N S L G A R G . . . . . . . .

Fig. 4. (a) Deduced amino acid sequence of $P$. denitrificans CcmA (pdecma). Residues forming the predicted ATP-binding site are shown in white on black. (b, c) Comparisons (b) of the deduced amino acid sequence of $P$. denitrificans $C \mathrm{~cm} B$ (pdccmb) with those of Rhodobacter capsulatus HelB (rchelb), Bradyrhizobium japonicum CycW (bjcycw), Rhizobium etli CcmB (reccmb), E. coli CcmB (ecccmb) and the predicted product of the Haemophilus influenzae ORF HI1090 (hiccmb), and (c) of the deduced amino acid sequence of $P$. denitrificans $\mathbf{C c m C}$ (pdccmc) with those of $R$. capsulatus HelC (rchelc) and the predicted B. japonicum orf263 (bjo263), H. influenzae ORF HI1091 (hiccmc) and Pseudomonas fluorescens cyt1 (pfcyt1) gene products. Residues conserved in four or more sequences are boxed. Predicted membrane-spanning $\alpha$-helices in $\mathrm{CcmB} / \mathrm{HelB} / \mathrm{CycW}$ and $\mathrm{CcmC} / \mathrm{HelC} /$ the predicted orf263 and cyt1 gene products are indicated by the barrel-like symbols above the sequences. The predicted orientations of these $\alpha$-helices with respect to the inner (i.e. cytoplasmic) and outer (i.e. periplasmic) faces of the cytoplasmic membrane are indicated by the letters $i$ and $o$ at the helix ends. Conserved residues, or residues in the ILV (i.e. small hydrophobic sidechain) conservation group, proposed to form, or to contribute to, a motif mediating the interaction of $\mathrm{CcmB} / \mathrm{HelB} / \mathrm{CycW}$ and $\mathrm{CcmC/HelC/the} \mathrm{predicted} \mathrm{orf263} \mathrm{and} \mathrm{cyt1} \mathrm{gene} \mathrm{products}$ with the cognate CcmA/HelAVCycV components (see text), are shown in white on black. Substitutions of $T$ (bjcycW) or $A$ (reccmb, bjo263, pfcyt1) for the glycine residue usually invariant in this motif are shaded. Changes to $P$. fluorescens cyt1, thus correcting two frameshifts to restore obvious homology with the other gene products shown in (c), were made by deleting a $\mathrm{G}$ residue at position 233 and inserting one at position 391; the cyt1 start codon was also reassigned (from ATG at positions 144-146 to ATG at positions 107-109; numbering from Gaballa et al., 1995) to extend the N-terminal region of Cyt1.

E. coli and $H$. influenzae. Additionally, $\mathrm{CcmB}$ is homologous to the predicted Rhizobium etli $\mathrm{CcmB}$ (Aguilar \& Soberon, 1996) and CcmC to the predicted product of the Pseudomonas fluorescens cyt1 gene (Gaballa et al., 1995). CcmB and CcmC also exhibit extensive similarity to the predicted products of ORFs in 
the mitochondrial and chloroplast genomes of a number of eukaryotes, for example ORF277 and ORF228 in the mitochondrial genome of Marchantia polymorpha (Oda et al., 1992) and ORF206 and ORF250 in the chloroplast genome of Oenothera berteriana (Schuster, 1994; Jekabsons \& Schuster, 1995). The tryptophan-rich motif identified in the $c c m C /$ belC/orf 263 gene products (Thöny-Meyer et al., 1994) is completely conserved in $\mathrm{CcmC}$ of $P$. denitrificans.

The integral membrane components of bacterial periplasmic-binding-protein-dependent transporters (PBTs) contain a short conserved motif, EAA- $\mathrm{X}_{3}-\mathrm{G}-\mathrm{X}_{9}$ IXLP, proposed to mediate their interaction with the more hydrophilic subunit(s) that catalyse ATP hydrolysis (Dassa \& Hofnung, 1985). A statistical analysis of 45 PBT sequences led Köster \& Böhm (1992) to define a longer consensus motif, RL(E/L)-LP-(E/D)L(E/D)(E/ D)AARALG (A/L)(S/N)PW (R/Q)TFF(K/R)(L/V)LLPLA. This motif has not hitherto been identified in either the predicted $c \mathrm{cmB} / \mathrm{helB} / \mathrm{cycW}$ or the $c \mathrm{cmC} /$ helC/orf263 gene products; however, elements of it are clearly conserved in both groups of proteins (Fig. 4). In the $\mathrm{CcmB} / \mathrm{HelB} / \mathrm{CycW}$ group of proteins the conserved motif L-X ${ }_{6}$-GAA- $\mathrm{X}_{3}-\mathrm{GL}-\mathrm{X}_{9}$-LVLPL is found, while the predicted $c \mathrm{~cm} C$, helC, orf 263 and $c y t 1$ gene products contain the conserved motif $\mathrm{L}-\mathrm{X}_{9}-\mathrm{AA}(\mathrm{R} / \mathrm{K}) \mathrm{A}-\mathrm{G}-\mathrm{X}_{7}$ $(\mathrm{I} / \mathrm{V}) \mathrm{XLP}(\mathrm{I} / \mathrm{L})$ plus acidic residues in positions -7 or -9 relative to the conserved glycine residue. This usually invariant glycine residue is replaced by $\mathrm{T}$ in $\mathrm{CycW}$ and by $\mathrm{A}$ in the predicted orf 263 , cyt1 and Rhizobium etli $c \mathrm{cmB}$ gene products, but substitution of this residue, e.g. by alanine, by directed mutagenesis is tolerated in FhuB of E. coli (Köster \& Böhm, 1992). Furthermore, the present new analyses of transmembrane topology suggest that in both groups of proteins these conserved motifs span a cytoplasmic loop between the fourth and fifth predicted transmembrane helices, as shown for other PBT membrane-integral subunits (Dassa \& Hofnung, 1985). This analysis suggests that in $P$. denitrificans both $\mathrm{CcmB}$ and $\mathrm{CcmC}$ have the potential to interact with $\mathrm{CcmA}$, and that the same is true for the corresponding gene products in other bacteria. Since a typical prokaryotic ABC-transporter is formed of four membrane-associated protein domains, two membrane-integral and two ATPhydrolysing (Higgins, 1992), the putative transporter formed by $\mathrm{CcmA}, \mathrm{CcmB}$ and $\mathrm{CcmC}$ of $P$. denitrificans most likely has the subunit structure $(\mathrm{CcmA})_{2}-\mathrm{CcmB}$ $\mathrm{CcmC}$, similar to that of (for example) the histidine transporter ([HisP $]_{2}-$ HisQ-HisM) of Salmonella typhimurium (Ames \& Lecar, 1992) and the E. coli maltose transporter (MalF-MalG-[MalK] $]_{2}$ )(Dassa et al., 1993). It has been suggested previously that HelA, HelB and HelC may form a complex with this structure in $R$. capsulatus (Kranz \& Beckman, 1995) but this is the first time to our knowledge that any evidence for a particular subunit organisation of the putative transporter has been presented.

While the suggestion that the substrate for the putative transporter formed by the $c c m A B C /$ helABC/cycVW-
( \pm orf263) gene products may be haem (Ramseier et al., 1991; Beckman et al., 1992; Thöny-Meyer et al., 1994) has been widely accepted, no experimental evidence supporting this assignment has been presented. An ABCtype transporter, bemUV, mediating haem import in Yersinia enterocolitica has recently been described; the hem $V$ gene product is predicted to be the ATPhydrolysing component of this transporter, while the product of the bemU gene is predicted to be an integral membrane protein with six transmembrane helices (Stolilikovic \& Hantke, 1994). The substrate specificity of $\mathrm{ABC}$ transporters is determined by the sequence $(\mathrm{s})$ of the membrane-integral component(s) (Hekstra \& Tommassen, 1993; Higgins, 1992). Comparison of the sequences of the $P$. denitrificans $\mathrm{CcmB}$ and $\mathrm{CcmC}$ and homologous gene products with the predicted product of $Y$. enterocolitica bemU indicated very limited homology between either the predicted $c \mathrm{cmB} / \mathrm{helB} /$ $c y c W$ gene products and HemU or between HemU and the predicted $\mathrm{ccmC} /$ helC/orf 263 gene products. HemU is, in contrast, clearly homologous to the integral membrane subunits of $\mathrm{ABC}$-transporters implicated in the uptake of ferrisiderophores, ferric dicitrate and vitamin $\mathrm{B}_{12}$, the corrin ring of which resembles the porphyrin ring of haem (Stojiljkovic \& Hantke, 1994). These proteins exhibit extensive sequence homology over their whole lengths and certain highly conserved motifs (e.g. -RLPR-, -RNP- and -F(I/V)GL-) have been identified (Staudenmaier et al., 1989). None of these motifs could be identified in the $c \mathrm{cmB} / \mathrm{helB} / \mathrm{cycW}$ or $\mathrm{ccmc} /$ helc/orf 263 gene products. The only motif shared between the $\mathrm{CcmB} / \mathrm{CcmC}$ group and the iron complex transporters is that proposed to mediate interaction with the ATP-binding subunits as discussed above. A similar concentration of positive charges at the C-termini of the $\mathrm{CcmC}$ group and the iron-complex transporters (Staudenmaier et al., 1989) may be related to membrane insertion (von Heijne, 1992). The outermembrane haem receptor, HutA, of Vibrio cholerae has been reported to have a haem-binding pocket similar to that observed in the horse haemoglobin $\varsigma$ chain (Henderson \& Payne, 1994); conserved residues which might form a similar feature could not be identified in $\mathrm{CcmB}$ or $\mathrm{CcmC}$. The possibility that $\mathrm{CcmB}$ or $\mathrm{CcmC}$, or both, contain a novel motif associated with haem binding and/or translocation cannot be ruled out; indeed, it has been suggested that the tryptophan-rich regions of the $\mathrm{ccmC} /$ helC/orf 263 gene products may bind haem (Beckman et al., 1992; Thöny-Meyer et al., 1994). However, analyses of the topology of this group of proteins place this motif in a periplasmic loop rather than in a membrane-spanning region (Fig. 4; ThönyMeyer et al., 1994), suggesting that while it may bind haem it is unlikely to contribute directly to its transport across the cytoplasmic membrane. Thus a role for the putative $\mathrm{CcmABC}$ transporter in haem transport cannot be inferred from the predicted amino acid sequences of $\mathrm{CcmB}$ or $\mathrm{CcmC}$. We note also that there is little similarity between $\mathrm{CcmB}$ and $\mathrm{CcmC}$ and the $\mathrm{CydC}$ and CycD gene products suggested to mediate export of haem $d$ and possibly protohaem in E. coli (Poole et al., 

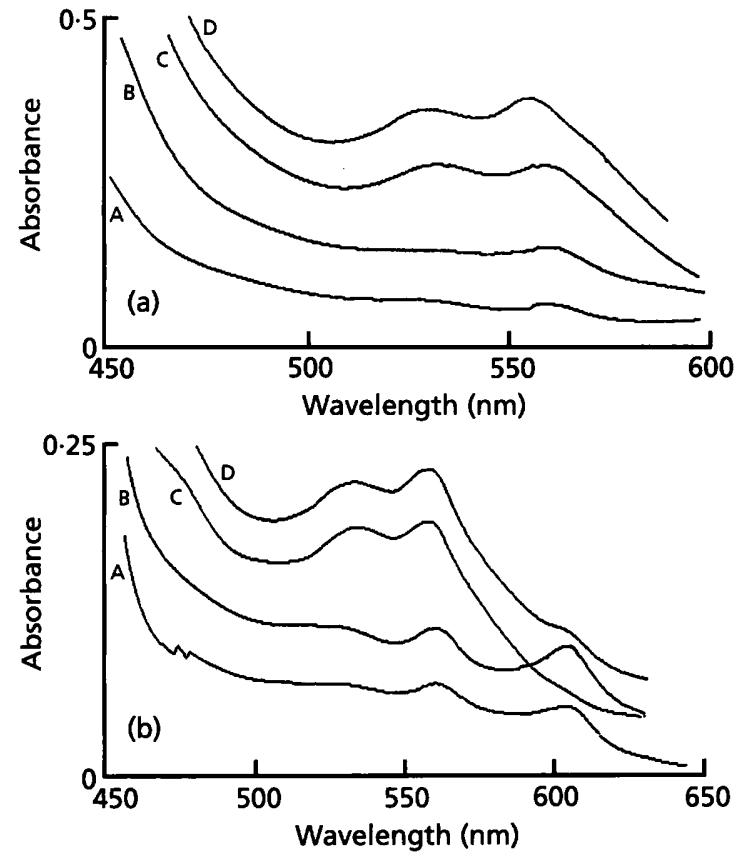

Fig. 5. Visible absorption spectra of total soluble (a) and membrane (b) fractions from $P$. denitrificans mutants HN49 and HN53 grown in the presence and absence of haemin $(4.5 \mu \mathrm{M})$. Strains were grown with choline as carbon and energy source to maximize c-type cytochrome expression. Traces A and B, HN49 and HN53, respectively, grown without added haemin; traces C and D, HN49 and HN53, respectively, grown with added haemin. Total soluble extracts were adjusted to $15 \mathrm{mg}$ protein $\mathrm{ml}^{-1}$. Membrane samples contained $10 \mathrm{mg}$ dodecylmaltoside-solubilized protein $\mathrm{ml}^{-1}$. All samples were reduced with sodium dithionite and spectra measured against a buffer reference.

1993, 1994) and that these latter gene products show only extremely limited similarity to HemU or the membrane-integral components of other iron-complex transporters.

\section{Exogenous haem does not stimulate c-type cytochrome synthesis in HN49 or HN53}

If the $c c m A B C$ genes code for an outwardly directed haem transporter, it might be possible to restore c-type cytochrome biosynthesis in HN49 and HN53 by the external addition of haem, provided the latter is able to enter the periplasm and interact with the $c$-type cytochrome biosynthetic apparatus. Mutants HN49 and HN53 were grown aerobically with choline (to maximize expression of $c$-type cytochrome polypeptides), in the presence and absence of added haemin $(4.5 \mu \mathrm{M})$, and total soluble and cytoplasmic membrane fractions were prepared and analysed by spectroscopy. No absorbance at $550 \mathrm{~nm}$, which would indicate the formation of $c$-type cytochromes, was observed in either soluble or membrane fractions from M49 or M53 grown with added haemin (Fig. 5a, b). However, total soluble fractions of HN53 and HN49 grown in the presence of haemin exhibited increased (two- to threefold) absorbance maxima at 560 and $535 \mathrm{~nm}$, indicating increased levels of soluble haemoproteins compared to total soluble fractions from cells grown in the absence of haemin (Fig. 5a). Cytoplasmic membranes from HN49 and HN53 grown in the presence of haemin also exhibited increased (two- to threefold) absorbance maxima at 560 and $535 \mathrm{~nm}$, indicating increased levels of $b$-type cytochromes compared to membranes from cells grown without added haem (Fig. 5 b). In all cases the cells were grown in iron-sufficient media, so it is unlikely that the increased cytochrome content of the cells grown in the presence of haem is the result of an increase in the amount of iron available for cytochrome formation. The increased levels of haemoproteins observed may result from association of haem with preformed apohaemoproteins (as reported for E. coli; Haddock \& Schairer, 1973) or from increased apohaemoprotein expression followed by association of these apohaemoproteins with free haem. Whichever is the case, these results indicate that haemin added to growth media is able to cross both outer and inner membranes of $P$. denitrificans. This conclusion is supported by the observation that membranes from both HN49 and HN53 grown in the presence of haem contained reduced levels of cytochrome $a a_{3}$ as judged by a reduction in the characteristic absorbance peak at $604 \mathrm{~nm}$. This may be due either to inhibition by haem of the enzymes converting haem to haem $a$ or to the $a a_{3}$ oxidase being repressed.

While elimination of a role for $\mathrm{CcmA}$ or $\mathrm{CcmB}$ in haem transport would be consistent with the lack of sequence similarity between $\mathrm{CcmB}$ and $\mathrm{CcmC}$ and the membraneintegral components of iron-complex transporters (see above), failure of complementation by exogenous haem of a mutant putatively disrupted in haem export could be due to haem ligation to apocytochromes $c$ occurring only within a protein complex interacting with and occluding a hypothetical outwardly directed haem transporter channel; in this case the active site might not be accessible to exogenous haem.

Dumont et al. (1994) have reported that yeast mitochondrial apocytochrome $c$ can bind haem noncovalently and fold to a more compact (and hence possibly protease-resistant) form. This observation, while in conflict with previous reports (Fisher et al., 1973), suggests a mechanism whereby disruption of haem export to the periplasm in P. denitrificans could lead to an increased rate of degradation of periplasmic apocytochrome $c_{550}$ and thus to the reduced levels of apocytochrome $c_{550}$ observed in HN49 and HN53. Mutants HN49 and HN53 were therefore grown aerobically in minimal succinate media in the presence and absence of haemin $(4.5 \mu \mathrm{M})$ and total soluble fractions were prepared and analysed by SDS-PAGE and immunoblotting. No effect of haemin on apocytochrome $c_{550}$ levels was observed (data not shown). 
Table 1. Determination of alkaline phosphatase activities in $P$. denitrificans strains expressing an (apo-) cytochrome $c_{550}$-alkaline phosphatase fusion protein

Cells were grown to mid-exponential phase $\left(\mathrm{OD}_{650} 0 \cdot 6-0 \cdot 7\right)$. Means of three determinations on each of two cultures are shown. Activities are expressed as the difference between mean activities of cells containing pEPD60 and the corresponding plasmidless strains grown under the same conditions.

\begin{tabular}{|c|c|c|}
\hline \multirow[t]{2}{*}{ Strain } & \multicolumn{2}{|c|}{$\begin{array}{l}\text { Alkaline phosphatase } \\
\text { specific activity } \\
\text { (nmol } o \text {-NPP } \\
\text { hydrolysed } \mathrm{min}^{-1} \mathrm{mg}^{-1} \text { ) }\end{array}$} \\
\hline & $\begin{array}{c}\text { Cells grown } \\
\text { with } \\
\text { succinate }\end{array}$ & $\begin{array}{c}\text { Cells grown } \\
\text { with } \\
\text { choline }\end{array}$ \\
\hline PD1222(pEPD60) & $3 \pm 2$ & $29 \pm 3$ \\
\hline DP108(pEPD60) & $4 \pm 2$ & $34 \pm 3$ \\
\hline HN53(pEPD60) & $4 \pm 2$ & $28 \pm 4$ \\
\hline
\end{tabular}

\section{Analysis of expression and translocation of a cytochrome $c_{550}$-alkaline phosphatase fusion protein in mutant HN53}

A cytochrome $c_{550}$-alkaline phosphatase fusion protein was efficiently translocated to the periplasm in HN53. Plasmid pEPD60, carrying a $c y c A-p h o A$ fusion under the control of the $c y c A$ promoter and upstream regulatory regions, has been used as a reporter of $c y c A$ expression in P. denitrificans (Stoll et al., 1996); since active $E$. coli alkaline phosphatase is only assembled in the periplasm (Hoffman \& Wright, 1985), the fusion protein also acts as a reporter of its own translocation. pEPD60 was introduced by conjugation into HN53 and the $c y c H$ mutant DP108 and the exconjugants were analysed for expression of active alkaline phosphatase. Similar levels of alkaline phosphatase activity, indicating similar levels of expression and translocation of the (apo- or holo-) cytochrome $c_{550}$-alkaline phosphatase fusion protein, were detected in the two mutant strains and in the parental strain PD1222 (Table 1). These results agree with similar studies on corresponding mutants of Rhodobacter capsulatus (Beckman et al., 1992) and B. japonicum (unpublished data cited by Thöny-Meyer et al., 1994). Increased levels of alkaline phosphatase activity were measured in PD1222(pEPD60) when this strain was grown with choline rather than succinate as sole carbon source, indicating increased expression of the cytochrome $c_{550}-$ alkaline phosphatase fusion protein (Stoll et al., 1996). A similar increase was recorded in choline-grown HN53(pEPD60) (Table 1); this result suggests that regulation of $c y c A$ is unaffected by the mutation in HN53. Total soluble fractions prepared from the pEPD60-harbouring strains were analysed by SDSPAGE and either haem staining or immunoblotting with antibodies to $E$. coli alkaline phosphatase. A haem- (a)

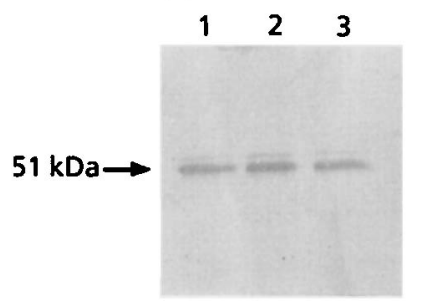

(b)

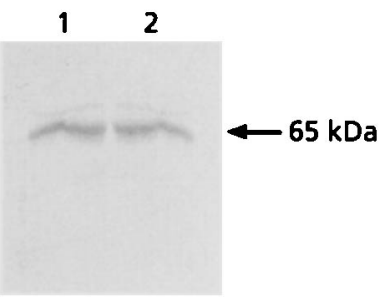

Fig. 6. Analysis of apocytochrome expression and accumulation in HN53. (a) Detection of a cytochrome $c_{550}$-alkaline phosphatase fusion protein in total soluble extracts from $P$. denitrificans strains carrying a cycA-phoA fusion cloned in a broad-host-range vector. Proteins were separated by SDS-PAGE and the fusion protein detected by immunoblotting. Lanes: 1, PD1222(pEPD60); 2, DP108(pEPD60); 3, HN53(pEPD60). Lanes contained approximately $20 \mu \mathrm{g}$ total protein. (b) Detection of apocytochrome $\mathrm{cd}_{1}$ (apo-nitrite reductase) in total soluble extracts from $P$. denitrificans mutants HN53 (lane 1) and DP108 (cych) (lane 2). Bacteria were grown aerobically to midexponential phase and then incubated anaerobically with $20 \mathrm{mM} \mathrm{KNO}_{3}$ for $5.5 \mathrm{~h}$ prior to harvesting. Proteins were separated by SDS-PAGE and apocytochrome cd, was detected by immunoblotting with antisera raised against the holocytochrome. Lanes contained approximately $40 \mu \mathrm{g}$ total protein.

staining band with a molecular mass of $51 \mathrm{kDa}$, the predicted molecular mass of the cytochrome $c_{550^{-}}$ alkaline phosphatase fusion protein, was detected in PD1222(pEPD60) but not in DP108(pEPD60) or in HN53(pEPD60). Total soluble extracts from cholinegrown PD1222 contained no $51 \mathrm{kDa}$ haem-staining protein. Antibodies to E. coli alkaline phosphatase detected a $51 \mathrm{kDa}$ polypeptide in soluble extracts from all three recombinant strains (but not in PD1222, DP108 or HN53), indicating that both DP108(pEPD60) and HN53(pEPD60) accumulated an intact apocytochrome $c_{550} 0^{-a l k a l i n e}$ phosphatase fusion protein; immunoreactive material with a molecular mass lower than $51 \mathrm{kDa}$ was not observed, indicating that the apocytochrome $c_{550}$ domain of the fusion protein was not proteolytically degraded to a significant extent in either of these strains (Fig 6a).

\section{Analysis of apocytochrome $\mathrm{Cd}_{1}$ expression and accumulation in mutant HN53}

We have previously reported that a $c$-type cytochrome deficient mutant of $P$. denitrificans, HUUG 25 , obtained by chemical mutagenesis and of unknown genotype, accumulates apocytochrome $c d_{1}$ (aponitrite reductase) when incubated anaerobically with nitrate after a period of aerobic growth (Page $\&$ Ferguson, 1989). In a similar experiment, HN53 and the $c y c H$ mutant DP108 were grown aerobically to mid-exponential phase and then incubated anaerobically with nitrate. Under these conditions both DP108 and HN53 accumulated apocytochrome $c d_{1}$ as judged by SDS-PAGE and immunoblotting of total soluble extracts. Comparison of the intensity of bands produced on immunoblotting suggested that the two mutants accumulated similar 
amounts of apocytochrome $c d_{1}$ when induced under similar conditions (Fig. 6b). The molecular masses of the cytochrome $c d_{1}$ polypeptides accumulated by DP108 and HN53 were identical to that of the holocytochrome purified from wild-type cells, indicating that apocytochrome $c d_{1}$ was translocated to the periplasm in both DP108 and HN53; this was confirmed by fractionation of cells followed by SDS-PAGE and immunoblotting (data not shown). Total soluble extracts from DP108 and HN53 grown aerobically to mid-exponential phase, but then harvested without exposure either to anaerobic conditions or to nitrate, contained no material reacting with antisera raised to cytochrome $c d_{1}$.

\section{DISCUSSION}

The present work extends knowledge of the $c c m A$, $c c m B$ and $c c m C$ gene products by presenting evidence that (i) they form a complex with organization $(\mathrm{CcmA})_{2}$ $\mathrm{CcmB}-\mathrm{CcmC}$, and (ii) that, contrary to previous suggestions (see Introduction), they transport neither $c$ type apocytochromes nor haem.

The failures of HN49 and HN53 to accumulate apocytochrome $c_{550}$ were initially thought to implicate $c c m A$ and $\mathrm{ccmB}$ in apocytochrome translocation. This was unexpected because the majority of bacterial $c$-type cytochromes studied to date are synthesized as precursors with conventional N-terminal signal peptides, and, as a consequence, are almost certain to be translocated in a sec-dependent manner rather than by a specific transporter (Kranz \& Beckman, 1995). The results obtained here with an apocytochrome $c_{550^{-}}$ alkaline phosphatase fusion protein and with apocytochrome $c d_{1}$ support this latter view and strongly suggest that the putative CcmABC-transporter is not a $c$-type apocytochrome exporter. Moreover, these results would appear to rule out a general protein translocation defect in HN53, the possibility of which was raised by the proximity of a homologue of the E. coli secF gene to ccmA.

The putative CcmABC-transporter might translocate some component other than haem required for $c$-type cytochrome biogenesis (Kranz \& Beckman, 1995); this could be any of the wide range of compounds transported by this class of membrane pump (Fath \& Kolter, 1993). A possible candidate might be a low molecular mass thiol or oxidized thiol compound; the thioldisulphide redox balance in the periplasm has been shown to influence $c$-type cytochrome biogenesis in E. coli (Crooke \& Cole, 1995; Sambongi \& Ferguson, $1994 \mathrm{~b}$; and unpublished data).

Why HN49 and HN53 fail to accumulate apocytochrome $c_{550}$ to the levels observed in other $c$-type cytochrome deficient mutants is unclear. The similar levels of expression of the $c y c A-p h o A$ fusion in PD1222 and $\mathrm{HN} 53$, and the observation that its expression is increased to a similar extent in choline-grown PD1222 and $\mathrm{HN} 53$, suggest that the expression and regulation of $c y c A$ in HN53 are probably normal. Possibly the simplest interpretation of the available data is that apocytochrome $c_{550}$ is translocated to the periplasm in HN49 and HN53 but is then degraded rapidly. We have previously inferred that the apocytochrome $c_{550}$ accumulated by $c$-type cytochrome deficient mutants of $P$. denitrificans is subject to a constant rate of proteolytic degradation (Page \& Ferguson, 1994). The absence of $\mathrm{CcmA}$ and/or $\mathrm{CcmB}, \mathrm{CcmC}, \mathrm{CcmD}$ or the product of the $c y c Y / h e l X / t l p B$ homologue presumed, by analogy with other organisms, to lie downstream of $c \mathrm{cmD}$, evidently promotes this process to a greater extent than absence of $\mathrm{CycH}$. Apocytochrome $c_{550}$ is thought to be susceptible to proteolysis due to its extended conformation (Page \& Ferguson, 1990, 1994). In contrast, apocytochrome $c d_{1}$ (aponitrite reductase) retains a compact conformation in spite of the absence of both $c$ and $d_{1}$ haems (Page $\&$ Ferguson, 1989) and is therefore not degraded, while the N-terminal portion of apocytochrome $c_{550}$ present in the apocytochrome $c_{550^{-}}$ alkaline phosphatase fusion protein may well be stablilized by interaction with its the folded alkaline phosphatase domain.

The role of the putative CcmABC complex has so far been discussed solely in terms of a transporter, but recent developments in the ABC-transporter field and the observation that disruption of the Saccharomyces cerevisiae mitochondrial ABC-transporter ATM1 results in a number of defects including, but not restricted to, loss of $c$-type cytochromes (Leighton $\&$ Schatz, 1995), suggest that the other possible functions for $\mathrm{CcmABC}$ ought to be considered. It is possible that the putative CcmABC transporter is not an ATP-driven membrane pump but instead is a passive channel, as has been shown for the cystic fibrosis transmembrane conductance regulator (CFTR), which has the appearance of an ABC-transporter but which is a chloride ion channel (reviewed by Ames \& Lecar, 1992). The putative CcmABC-transporter could also be bifunctional, regulating the activity of other membrane protein(s) independently of its own transporter/channel activity. This property is exhibited by the human multidrug resistance P-glycoprotein, which regulates a chloride ion channel, by CFTR, which regulates two chloride ion channels and a sodium ion channel, and in Salmonella typhimurum, where SapABCDF, an ATP-driven peptide transporter, regulates the activity of SapJ, a potassium ion channel (reviewed by Higgins, 1995). Were this to be the case for $C \mathrm{~cm} A B C$, the function regulated would obviously be one required for $c$-type cytochrome maturation but the species carried by the transporter/channel itself might not be directly required in the process of $c$-type cytochrome assembly. ABC-transporters also have the capacity for signal transduction (Petronilli \& Ames, 1991).

\section{ACKNOWLEDGEMENTS}

We gratefully thank $N$. Karpovich-Tate for technical assistance, A. de Boer and R. J. M. van Spanning for the gift of antiserum to nitrite reductase, $B$. Ludwig for antibodies to cytochromes $c_{1}$ and $c_{552}$, V. Cooper (OCMS) for oligo- 
nucleotide synthesis, and B. C. Berks and N. F. W. Saunders for advice on sequence analysis. This work was supported by BBSRC grant GR/H70348 to S.J.F. H.A.C.N. thanks the SERC for a research studentship. This is a contribution from the Oxford Centre for Molecular Sciences, which is supported by the BBSRC, EPSRC and MRC.

\section{REFERENCES}

Aguilar, G. R. \& Soberon, M. (1996). Cloning and sequence analysis of the Rhizobium etli $c \mathrm{~cm} A$ and $c \mathrm{cmB}$ genes involved in $c$-type cytochrome assembly. EMBL/GenBank/DDBJ database entry U52866.

Alefounder, P. R. \& Ferguson, S. J. (1981). A periplasmic location for methanol dehydrogenase from Paracoccus denitrificans: implications for proton pumping by cytochrome $a a_{3}$. Biochem Biophys Res Commun 98, 778-784.

Altschul, S. F., Gish, W., Miller, W., Myers, E. W. \& Lipman, D. J. (1990). Basic local alignment search tool. J Mol Biol 215, 403-410.

Ames, G. F.-L. \& Lecar, H. (1992). ATP-dependent bacterial transporters and cystic fibrosis: analogy between channels and transporters. FASEB J 6, 2660-2666.

Ames, G. F.-L., Mimura, C. S., Holbrook, S. R. \& Shymala, V. (1992). Traffic ATPases: a superfamily of transport proteins operating from Escherichia coli to humans. Adv Enzymol 65, $1-47$.

Auerswald, E.-A., Ludwig, G \& Schaller, H. (1981). Structural analysis of Tn5. Cold Spring Harbour Symp Quant Biol 45, 107-113.

Bagdasarian, M., Lüz, R., Rückert, B., Franklin, F. C. H., Bagdasarian, M. M., Frey, J. \& Timmis, K. N. (1981). Specificpurpose plasmid cloning vectors. II. Broad host range, high copy number RSF1010-derived vectors and a host-vector system for gene cloning in Pseudomonas. Gene 16, 237-247.

Beckman, D. L. \& Kranz, R. G. (1993). Cytochromes $c$ biogenesis in a photosynthetic bacterium requires a periplasmic thioredoxinlike protein. Proc Natl Acad Sci USA 90, 2179-2183.

Beckman, D. L., Trawick, D. R. \& Kranz, R. G. (1992). Bacterial cytochrome $c$ biogenesis. Genes Dev 6, 268-283.

Burnell, J. N., John, P. \& Whatley, F. R. (1975). The reversibility of active sulphate transport in membrane vesicles of Paracoccus denitrificans. Biochem J 150, 527-536.

Crooke, H. \& Cole, J. (1995). The biogenesis of $c$-type cytochromes in $E$. coli requires a membrane-bound protein, DipZ, with a protein disulphide isomerase-like domain. Mol Microbiol 15, 1139-1150.

Dassa, E. \& Hofnung, M. (1985). Sequence of gene malG in E. coli K12: homologies between integral membrane components from binding-protein-dependent transport systems. EMBO $J 4$, 2287-2293.

Dassa, E., Francoz, E., Dahl, M., Schneider, E., Werts, C., Charbit, A., Saurin, W. \& Hofnung, M. (1993). The maltose B region in Salmonella typhimurium, Escherichia coli and other enterobacteriaceae. NATO ASI Ser Ser A Life Sci 245, 91-104.

Devereux, J., Haeberli, P. \& Smithies, O. (1984). A comprehensive set of sequence analysis programs for the VAX. Nucleic Acids Res 12, 387-395.

Ditta, G., Stanfield, S., Corbin, D. \& Helinski, D. R. (1980). Broad host range DNA cloning systems for Gram-negative bacteria: construction of a gene bank of Rhizobium meliloti. Proc Natl Acad Sci USA 77, 7347-7351.

Dumont, M. E., Corin, A. F. \& Campbell, G. A. (1994). Noncovalent binding of heme induces a compact apocytochrome $c$ structure. Biochemistry 33, 7368-7378.

Fath, M. J. \& Kolter, R. (1993). ABC transporters: bacterial exporters. Microbiol Rev 57, 995-1017.

Fisher, W. R., Taniuchi, H. \& Anfinsen, C. B. (1973). On the role of heme in the formation of the structure of cytochrome $c . J$ Biol Chem 248, 3188-3195.

Fleischmann, R. D., Adams, M. D., White, O. \& 37 other authors (1995). Whole-genome sequencing and assembly of Haemophilus influenzae Rd. Science 269, 496-512.

Gaballa, A., Koedam, N. \& Cornelis, P. (1995). Pseudomonas fluorescens cyt $[1,2,3,4,5,6,7,8]$ genes. EMBL/GenBank/DDBJ database entry Z47979.

Gardel, C., Johnson, K., Jacq, A. \& Beckwith, J. (1990). The secD locus of $E$. coli codes for two membrane proteins required for protein export. EMBO J 9, 3209-3216.

Grove, J., Tanapongpipat, S., Thomas, G., Griffiths, L., Crooke, H. \& Cole, J. (1996). Escherichia coli K-12 genes essential for the synthesis of $c$-type cytochromes and a third nitrate reductase located in the periplasm. Mol Microbiol 19, 467-481.

Haddock, B. A. \& Schairer, H. U. (1973). Electron-transport chains of Escherichia coli: reconstitution of respiration in a 5 aminolevulinic acid-requiring mutant. Eur J Biochem 35, 34-45.

Harms, N. \& van Spanning, R. J. (1991). $C_{1}$ metabolism in Paracoccus denitrificans; genetics of $P$. denitrificans. $J$ Bioenerg Biomembr 23, 187-210.

Harms, N., de Vries, G. E., Maurer, K., Veltkamp, E. \& Stouthamer, A. H. (1985). Isolation and characterisation of Paracoccus denitrificans mutants with defects in the metabolism of onecarbon compounds. J Bacteriol 164, 1064-1070.

von Heijne, G. (1992). Membrane protein structure prediction. Hydrophobicity analysis and the positive-inside rule. J Mol Biol 225, 487-494.

Hekstra, D. \& Tommassen, J. (1993). Functional exchangeability of the $\mathrm{ABC}$ proteins of the periplasmic binding protein-dependent transport systems Ugp and Mal of Escherichia coli. J Bacteriol $175,6546-6552$.

Henderson, D. P. \& Payne, S. M. (1994). Characterisation of the Vibrio cholerae outer membrane heme transport protein HutA: sequence of the gene, regulation of expression, and homology to the family of TonB-dependent proteins. J Bacteriol 176, 3269-3277.

Higgins, C. F. (1992). ABC transporters: from microorganisms to man. Annu Rev Cell Biol 8, 67-113.

Higgins, C. F. (1995). The ABC of channel regulation. Cell 82, 693-696.

Higgins, C. F., Hiles, I. D., Salmond, G. P. C., Gill, D. R., Evans, J. A. D. I. J., Holland, I. B., Gray, J., Buckel, S. D., Bell, A. W. \& Hermodson, M. A. (1986). A family of related ATP-binding subunits coupled to many distinct biological processes in bacteria. Nature 323, 448-450.

Hoffman, C. S. \& Wright, A. (1985). Fusions of secreted proteins to alkaline phosphatase: An approach for studying protein secretion. Proc Natl Acad Sci USA 82, 5107-5111

Jekabsons, W. \& Schuster, W. (1995). orf250 encodes a second subunit of a ABC-type heme transporter in Oenothera mitochondria. Mol Gen Genet 246, 166-173.

Jones, D. T., Taylor, W. R. \& Thornton, J. M. (1994). A model recognition approach to the prediction of all-helical membrane protein structure and topology. Biochemistry 33, 3038-3049.

Karim, A., Kaderbhai, N., Evans, A., Harding, V. \& Kaderbhai, 
M. A. (1993). Efficient bacterial export of a eukaryotic cytoplasmic cytochrome. Bio/Technology 11, 612-618.

Koster, W. \& Bøhm, B. (1992). Point mutations in two conserved glycine residues within the integral membrane protein $F$ huB affect iron(III)hydroxamate transport. Mol Gen Genet 232, 399-407.

Kozak, M. (1983). Comparison of initiation in protein synthesis in procaryotes, eucaryotes, and organelles. Microbiol Rev 47, 1-45.

Kranz, R. G. \& Beckman, D. L. (1995). Cytochrome biogenesis. In Anoxygenic Photosynthetic Bacteria pp. 709-723. Edited by R. E. Blankenship, M. T. Madigan \& C. E. Bauer. Amsterdam: Kluwer.

Leighton, J. \& Schatz, G. (1995). An ABC transporter in the mitochondrial inner membrane is required for normal growth of yeast. EMBO J 14, 188-195.

Marrs, B. \& Gest, H. (1973). Genetic mutations affecting the respiratory electron-transport system of the photosynthetic bacterium Rhodopseudomonas capsulata. J Bacteriol 114, 1045-1051.

Moir, J. W. B. (1993). Aspects of electron transport in Thiosphaera pantotropha and Paracoccus denitrificans. DPhil thesis, University of Oxford.

Oda, K., Yamato, K., Ohta, E., Nakamura, Y., Takmura, M., Nozato, N., Kohchi, T., Ogura, Y., Kanegae, T., Akashi, K. \& Ohyama, K. (1992). Gene organisation deduced from the complete sequence of liverwort Marchantia polymorpha mitochondrial DNA. A primitive form of plant mitochondrial genome. $J \mathrm{Mol}$ Biol 223, 1-7.

Page, M. D. \& Ferguson, S. J. (1989). A bacterial $c$-type cytochrome can be translocated to the periplasm as an apo form; the biosynthesis of cytochrome $c d_{1}$ (nitrite reductase) from Paracoccus denitrificans. Mol Microbiol 3, 653-661.

Page, M. D. \& Ferguson, S. J. (1990). Apo forms of cytochrome $c_{550}$ and cytochrome $c d_{1}$ are translocated to the periplasm of Paracoccus denitrificans in the absence of haem incorporation caused by either mutation or inhibition of haem synthesis. $\mathrm{Mol}$ Microbiol 4, 1181-1192.

Page, M. D. \& Ferguson, S. J. (1994). Differential reduction in periplasmic and membrane-bound $c$-type cytochrome contents in a Paracoccus denitrificans mutant partially deficient in 5aminolevulinate synthase. J Bacteriol 176, 5919-5928.

Page, M. D. \& Ferguson, S. J. (1995). Cloning and sequence analysis of the $c y c H$ gene from Paracoccus denitrificans: the $c y c H$ gene product is required for assembly of all $c$-type cytochromes, including cytochrome $c_{1}$. Mol Microbiol 15, 307-318.

Persson, B. \& Argos, P. (1994). Prediction of transmembrane segments in proteins utilising multiple sequence alignments. $J$ Mol Biol 237, 182-192.

Petronilli, V. \& Ames, G. F.-L. (1991). Binding protein-independent histidine permease mutants: uncoupling of ATP hydrolysis from transmembrane signalling. J Biol Chem 266, 16293-16296.

Poole, R. K., Hatch, L., Cleeter, M. W. J., Gibson, F., Cox, G. B. \& Wu, G. (1993). Cytochrome bd biosynthesis in Escherichia coli: the sequences of the $c y d C$ and $c y d D$ genes suggest that they encode the components of an $\mathrm{ABC}$ membrane transporter. $\mathrm{Mol}$ Microbiol 10, 421-430.

Poole, R. K., Gibson, F. \& Wu, G. (1994). The $c y d D$ gene product, component of a heterodimeric $\mathrm{ABC}$ transporter, is required for assembly of periplasmic cytochrome $c$ and of cytochrome $b d$ in Escherichia coli. FEMS Microbiol Lett 117, 217-224.

Ramseier, T., Winteler, H. V. \& Hennecke, H. (1991). Discovery and sequence analysis of bacterial genes involved in the biogenesis of $c$-type cytochromes. J Biol Chem 266, 7793-7803.
Reizer, J., Reizer, A. \& Saier, M. H., Jr (1992). A new subfamily of bacterial ABC-transport systems catalyzing export of drugs and carbohydrates. Protein Sci 1, 1326-1332.

Richterich, P., Lakey, N., Gryan, G. Jaehn, L., Mintz, L., Robison, K. \& Church, G. M. (1993). Centisome 49 region of E. coli K-12 BHB2600. EMBL/GenBank/DDBJ database entry U00008.

Sambongi, Y. \& Ferguson, S. J. (1994a). Synthesis of holo Paracoccus denitrificans cytochrome $c_{550}$ requires targeting to the periplasm whereas that of holo Hydrogenobacter thermophilus cytochrome $c_{552}$ does not. Implications for $c$-type cytochrome biogenesis. FEBS Lett 340, 65-70.

Sambongi, Y. \& Ferguson, S. J. (1994b). Specific thiol compounds complement deficiency in $c$-type cytochrome biogenesis in Escherichia coli carrying a mutation in a membrane-bound disulphide-isomerase-like protein. FEBS Lett 353, 235-240.

Sambrook, J., Fritsch, E. F. \& Maniatis, T. (1989). Molecular Cloning: a Laboratory Manual, 2nd edn. Cold Spring Harbor, NY: Cold Spring Harbor Laboratory.

Schuster, W. (1994). The highly edited orf206 in Oenothera mitochondria may encode a component of a heme transporter involved in cytochrome $c$ biogenesis. Plant Mol Biol 25, 33-42.

Simon, R., Priefer, U. \& Puhler, A. (1983). A broad host range mobilization system for in vivo genetic engineering: transposon mutagenesis in Gram-negative bacteria. Bio/Technology 1, $37-45$.

Sockett, R. E. \& Armitage, J. P. (1991). Isolation, characterisation and complementation of a paralysed flagellar mutant of Rhodobacter sphaeroides WS8. J Bacteriol 173, 2786-2790.

Staudenmaier, H., van Hove, B., Yaraghi, Z. \& Braun, V. (1989). Nucleotide sequences of the $f e c B C D E$ genes and locations of the proteins suggest a periplasmic-binding-protein-dependent transport mechanism for iron(III) dicitrate in Escherichia coli. $J$ Bacteriol 171, 2626-2633.

Steinrucke, P. \& Ludwig, B. (1993). Genetics of Paracoccus denitrificans. FEMS Microbiol Rev 104, 83-118.

Stojijkovic, I. \& Hantke, K. (1994). Transport of haemin across the cytoplasmic membrane through a haemin-specific periplasmicbinding-protein-dependent transport system in Yersinia enterocolitica. Mol Microbiol 13, 7719-7732.

Stoll, R., Page, M. D., Sambongi, Y. \& Ferguson, S. J. (1996). Cytochrome $c_{550}$ expression in Paracoccus denitrificans strongly depends on growth condition; identification of promoter region for $c y c A$ by transcription start analysis. Microbiology 142, 2577-2585.

Thøny-Meyer, L., Ritz, D. \& Hennecke, H. (1994). Cytochrome $c$ biogenesis in bacteria : a possible pathway begins to emerge. $\mathrm{Mol}$ Microbiol 12, 1-9.

Thøny-Meyer, L., Fischer, F., Kunzler, P., Ritz, D. \& Hennecke, H. (1995). Escherichia coli genes required for c-type cytochrome maturation J Bacteriol 177, 4321-4326.

Thöny-Meyer, L., Kunzler, P. \& Hennecke, H. (1996). Requirements for maturation of Bradyrhizobium japonicum cytochrome $c_{550}$ in Escherichia coli. Eur J Biochem 235, 754-761.

van Verseveld, H. W., Krab, K. \& Stouthamer, A. H. (1981). Proton pump coupled to cytochrome $c$ oxidase in Paracoccus denitrificans. Biochim Biophys Acta 635, 525-534

Viebrock, A. \& Zumft, W. G. (1987). Physical mapping of transposon $\operatorname{Tn} 5$ insertions defines a gene cluster functional in nitrous oxide respiration by Pseudomonas stutzeri. J Bacteriol $169,4577-4580$.

de Vries, G. E., Harms, N., Hoogedijk, J. J. \& Stouthamer, A. H. 
(1989). Isolation and characterisation of Paracoccus denitrificans mutants with increased conjugation frequencies and pleiotropic loss of a (nGATCn) DNA-modifying property. Arch Microbiol $152,52-57$.

Walker, J. E., Saraste, M., Runswick, M. J. \& Gay, N. J. (1982).

Distantly related sequences in the $\alpha$ - and $\beta$-subunits of ATP synthase, myosin, kinases and other ATP-requiring enzymes and a common nucleotide binding fold. EMBO J 1, 945-951.

Willison J. C. \& John, P. (1979). Mutants of Paracoccus denitrificans deficient in c-type cytochromes. J Gen Microbiol 115, 443-450.

Yanisch-Perron, C., Vieira, J. \& Messing, J. (1985). Improved M13 phage cloning vectors and host strains: nucleotide sequences of the M13mp18 and pUC19 vectors. Gene 33, 103-119.

Received 7 August 1996; revised 12 September 1996; accepted 16 September 1996. 